\title{
Queixas Musculoesqueléticas em Músicos: Prevalência e Fatores de Risco
}

\section{Playing-Related Musculoskeletal Complaints Among Musicians: Prevalence and Risk Factors}

\author{
Annemarie Frank ${ }^{(1)}$, Carlos Alberto von Mühlen ${ }^{(2)}$
}

\begin{abstract}
RESUMO
Disfunções musculoesqueléticas relacionadas à prática instrumental são freqüentes entre músicos, atingindo acima de $70 \%$ dos componentes de orquestras. O exercício da música como profissão requer ampla diferenciação e produtividade de capacidades tanto psicológicas, mentais, como também físicas. Muitos fatores de risco contribuem para o surgimento de queixas musculoesqueléticas durante a prática musical, entre eles: a técnica individual, as condições físicas do músico e o instrumento em si. Podem ocorrer distúrbios reumatológicos, neurológicos, dermatológicos e psicológicos, assim como problemas de visão e audição e do complexo orofacial. As queixas no aparelho motor manifestamse, muitas vezes, como dor, fraqueza ou tensão. Os diagnósticos do membro superior mais freqüentemente estabelecidos são as tendinopatias, mialgias e a síndrome do superuso. O médico e o terapeuta responsáveis devem conhecer as atividades e cargas do músico profissional, para que sejam proporcionadas avaliação e estratégia terapêutica adequadas.
\end{abstract}

Palavras-chave: músicos, doenças ocupacionais, reumatismo de partes moles, dor musculoesquelética.

\section{INTRODUÇÃO}

Ter o exercício da música como profissão geralmente passa a impressão da harmonia perfeita entre o ser humano e o instrumento, da combinação gratificante entre o prazer de tocar e o dia-a-dia profissional. Concertos inesquecíveis, como resultado de longos meses de preparo e ensaios, mostram-nos a parte bela dessa atividade. No entanto, esquecemos o imenso esforço que a música requer em termos de concentração, processamento multissensorial de informações e memória. Ela exige um empenho excepcional no que se refere a flexibilidade, condição, coordenação e motricidade

\begin{abstract}
Playing-related musculoskeletal complaints are often found among musicians, taking a toll in more than $70 \%$ of professional musicians in orchestras. Professional musical performance requires a high level of differenciation and efficiency of psychological, mental and physical skills. Many risk factors can contribute to the development of musculoskeletal conditions in this special population, like the individual technique, physical fitness of the musician and the instrument itself. Many rheumatic, neurological, dermatological, and psychiatric problems are reported, as well as dysfunctions of the visual, auditive and oral system. The musculoskeletal complaints often manifest as pain, weakness or tension, and the most common diagnoses of the upper limb are tendinopathies, myalgia and overuse syndromes. It is necessary for the skilfull physician and physical therapist to have a thorough knowledge about potential problems of the performing artist, in order to provide adequate medical examination and treatment to this very special patient.
\end{abstract}

Keywords: musicians, occupational diseases, soft tissue rheumatism, musculoskeletal pain.

fina, ao mesmo tempo que a era da gravação digital espera do músico um resultado cada vez mais perfeito.

A carga física e psíquica à qual está exposto o músico é enorme. As conseqüências desse fato abrangem um amplo espectro de alterações de saúde. Além de queixas no sistema motor, as quais enfoca este texto, também ocorrem disfunções do sistema nervoso, da pele, da respiração, problemas psíquicos, da visão e audição, além de afecções do complexo orofacial ${ }^{(1,2)}$.

Algumas dessas ocorrências foram observadas em tempos passados. Já no século 18, Ramazzini ${ }^{(3)}$ alertava para as queixas de artistas e artesãos; entre elas, “... tensão do

Recebido em 08/1 1/06. Aprovado, após revisão, em 26/03/07.

1. Fisioterapeuta do Instituto de Medicina Física e Reabilitativa, Klinikum Ingolstadt, República Federal da Alemanha, pianista acompanhadora e flautista

2. Professor titular de Reumatologia da Faculdade de Medicina da PUC-RS, Porto Alegre (RS), e pianista pela Escola de Artes da Universidade Federal do Rio Grande do Sul (UFRGS).

Endereço para correspondência: Annemarie Frank, Werdenfelser Strasse 7, 85049 Ingolstadt, Alemanha, telefone: 49 841 981 8797, e-mail: afrankbrasil@hotmail.com. 
crânio/batimento temporal/batimento cerebral/inchaço dos olhos e zumbido dos ouvidos...”. Segundo ele, a inspiração profunda, necessária ao tocar um instrumento de sopro, provocaria o "alongamento dos músculos" e a conseqüente "retenção do sangue".

A medicina do músico tem se desenvolvido em diversas direções e de forma mais aprofundada. Nos últimos 25 anos, médicos, terapeutas e pedagogos, assim como na medicina do esporte, buscaram informações mais detalhadas a respeito dos efeitos do instrumento sobre o corpo. Existem, atualmente, várias agremiações que se dedicam a esse assunto $^{(1)}$, como, por exemplo, a Performing Arts Medicine Association (PAMA), nos Estados Unidos, e a alemã Deutsche Gesellschaft für Musikphysiologie und Musikermedizin (DGfMM). Uma revista especializada, a Medical Problems of Performing Artists (Hanley \& Belfus Inc., ISSN 08851158), é publicada de forma quadrimestral pela PAMA.

O reconhecimento de distúrbios derivados da prática musical requer conhecimento específico dos movimentos envolvidos na técnica instrumental, do ensino e estudo da música, da situação de trabalho do músico, mas também das características dos instrumentos musicais, uma vez que o surgimento de um problema ocorre quase sempre de modo multifatorial. Entre os fatores de risco mais importantes que levam ao superuso das estruturas do sistema motor estão a forma e o tamanho do instrumento, a técnica, o tempo de trabalho dedicado ao instrumento, as condições de clima e espaço de trabalho, o comportamento de estudo e ensaio, as estratégias de compensação e as condições corporais dos músicos ${ }^{(4)}$.

A prevalência geral de queixas musculoesqueléticas relativas à prática instrumental varia, nos trabalhos até hoje publicados, entre $26 \%$ e $87 \%$ da população de $\operatorname{músicos}^{(5,6)}$. Os tipos de queixas envolvem, entre outros, intensidades variáveis de dor, fraqueza, rigidez, fadiga e tensão.

Chama a atenção que partes específicas do corpo são mais afetadas, por dependência do instrumento tocado. São, por exemplo, locais de queixas mais intensas a coluna lombar de contrabaixistas e a mão esquerda de violinistas e violistas ${ }^{(7)}$. Mesmo que muitos instrumentos tenham características que os tornem fontes específicas para o aparecimento de certas afecções, não existe um ranking de instrumentos que mostre a freqüência absoluta de queixas.

Quando um diagnóstico é estabelecido, trata-se, no caso dos membros superiores, freqüentemente, de tendinopatias, mialgias e da síndrome do superuso ${ }^{(8-10)}$. O termo superuso (overuse) é muito comum na descrição das disfunções entre músicos, mas a definição varia entre os autores. Faz-se necessária, portanto, uma classificação mais exata, baseada em estudos fisiopatogênicos e epidemiológicos.

\section{A PROBLEMÁTICA DA PRÁTICA INSTRUMENTAL PARA O SISTEMA MOTOR - FATORES DE RISCO}

\section{FORMA DO INSTRUMENTO}

Cada instrumento tem um formato específico, que produz seu som típico. Causas históricas, artísticas e estéticas contribuíram para que essa forma não sofresse maiores modificações ao longo dos últimos séculos. A adaptação do corpo humano a essas características, no entanto, é feita à custa do movimento fisiológico. Em geral, a postura em relação ao instrumento é assimétrica e não-ergonômica (Figura 1). Assim, por exemplo, o violino requer uma posição extrema de rotação externa do ombro e supinação máxima constante do antebraço esquerdo. A conseqüente carga sobre os tendões da mão e dos dedos, do nervo ulnar e da musculatura adjacente ao ombro explica algumas das disfunções dolorosas em violinistas ${ }^{(2)}$. No fagote, por outro modo, o peso do instrumento (cerca de $6 \mathrm{~kg}$ ) é suportado quase somente por uma cinta ao pescoço, o que sobrecarrega a coluna cervical baixa ${ }^{(4)}$. Outro exemplo é a manipulação dos pedais do órgão pelos pés, o que retira a função de apoio dos membros inferiores e requer, conseqüentemente, uma atividade postural compensatória mais elevada da coluna lombar.

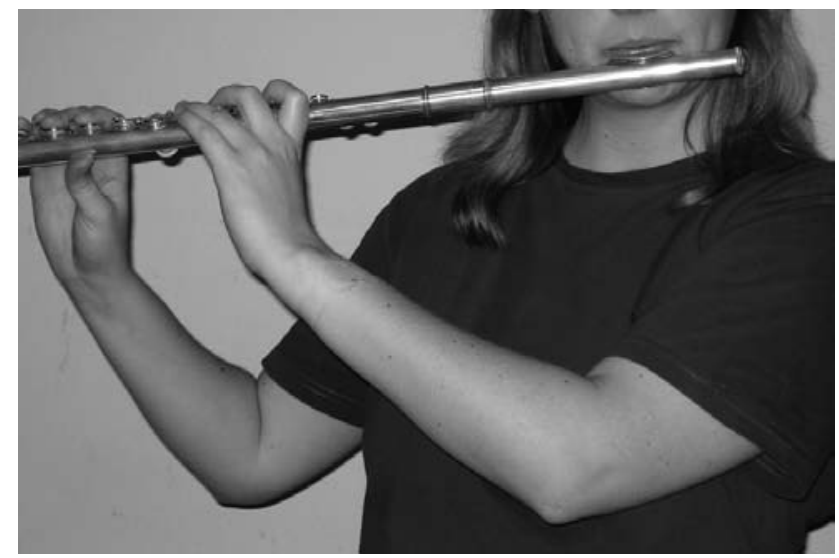

Figura 1 - A flauta transversa como exemplo da postura assimétrica ao instrumento, por si inadequada ergonomicamente.

\section{QUALIDADE DO INSTRUMENTO}

Há diferenças muito grandes em tamanho, peso, material e estrutura de instrumentos de diversos construtores, $\mathrm{O}$ 
que pode influenciar muito a produção musical. Teclas de piano pesadas para as mãos de uma criança, cordas grossas demais para os dedos delicados de uma violinista ou, então, uma viola de grande comprimento para um violista de braços curtos são exemplos da prática clínica que, no entanto, têm solução relativamente simples na mera adaptação das condições do instrumento ${ }^{(4)}$. Uma situação freqüente na clínica reumatológica são as consultas por dores geradas em períodos de adaptação do músico a um novo instrumento, a exemplo do tenista que troca a marca de sua raquete ou a empunhadura, ou, ainda, a tensão das suas cordas. Um instrumento novo traz novos ângulos de atuação mecânica, novas tensões musculares, ajustes finos e talvez até preocupações inconscientes de performance, tudo contribuindo para a geração de sintomas musculoesqueléticos.

\section{TÉCNICA}

A quantidade de força e o movimento ao tocar, somados ao trabalho de coordenação e motricidade fina, resultam na técnica individual do instrumentista, elaborada através de anos e fixada na memória sensitivo-motora. Essa técnica pode ser mais ou menos bem desenvolvida no que se refere a seqüências de movimento e tensões musculares fisiológicas, o que tem papel importante na origem de problemas. Como exemplo, entre violinistas existem métodos diferentes na postura dos dedos da mão esquerda, o que interfere diretamente no resultado musical e na carga sobre articulações e músculos (Figura 2). Também a posição e a técnica de uso do peso dos antebraços ao piano ou a escolha de dedilhados nos sopros de madeira são exemplos de fatores importantes. Cada modificação nesses critérios pode alterar o êxito da interpretação. Por isso, cabe ao médico, em conjunto com o terapeuta, escolher um caminho da reabilitação que promova a saúde do músico, sem acarretar quaisquer perdas na qualidade artística.

\section{REPERTÓRIO}

O programa a ser executado pelo músico pode ser o mais adequado às suas condições físicas. Ou não. Assim, pode acontecer, por vezes, um aumento muito rápido no nível do repertório ou podem algumas peças ser completamente inadequadas ao músico. Como exemplo, estudos de oitavas ou décimas para alunos de piano com pouca amplitude de mão entre primeiro e quinto dígitos. Peças que necessitem de um estudo mais aprofundado e/ou demorado também podem ocasionar sintomas de superuso, sem se esquecer de épocas em que são maiores as demandas de repertório,
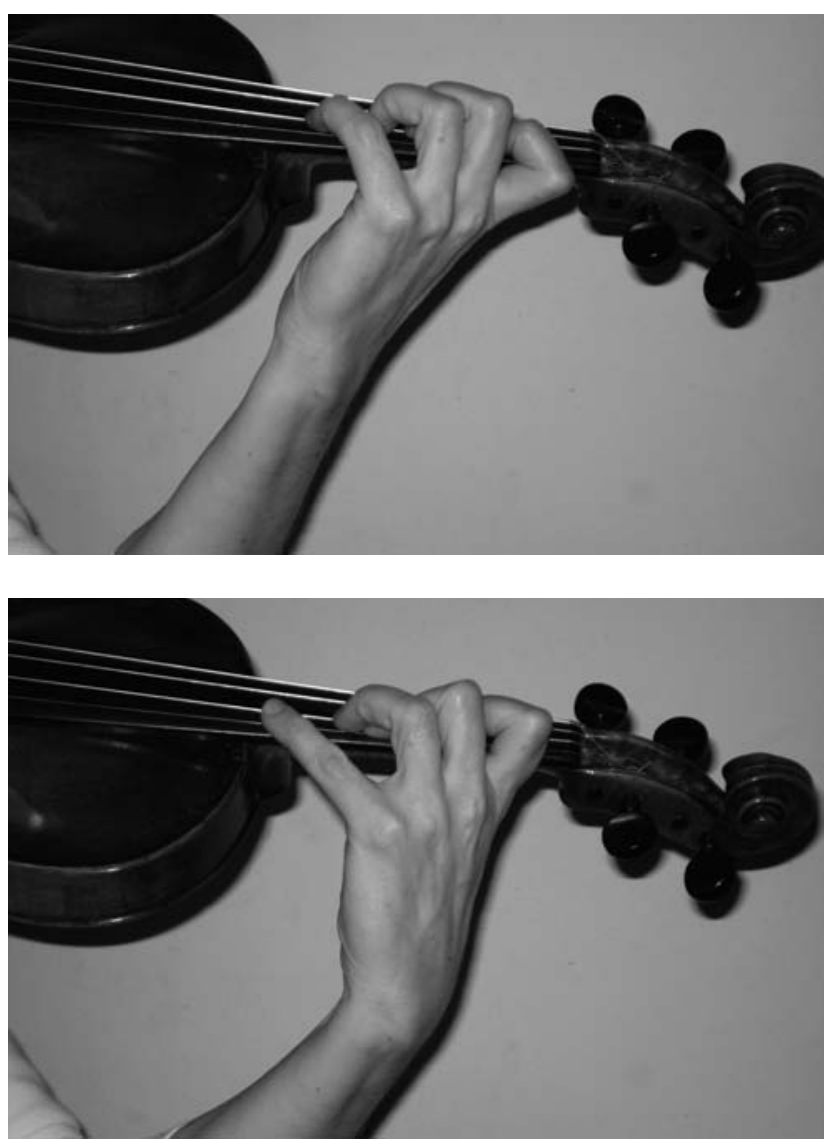

Figura 2 - Ao violino: a posição dos dedos da mão esquerda de forma arqueada e adaptada às cordas promove economia de movimentos e menor trabalho de força, enquanto a técnica de apoio na metade esquerda da polpa digital requer maior esforço do dedo mínimo em notas mais agudas.

como o início de semestre, cursos intensivos ou a preparação para concursos e concertos.

\section{EDUCAÇÃO MUSICAL}

$\mathrm{O}$ contato com o instrumento e a atitude diante de expectativas, situações de concerto e pressão, assim como a consciência corporal e a técnica instrumental, são forjados de modo intenso durante os primeiros anos de estudo. Assim como é possível, durante esse tempo, promover o desenvolvimento de talentos e da qualidade musical, muitos erros e maus hábitos podem instalar-se, sendo difícil a correção num período posterior. Freqüentemente, muitos problemas de saúde, inclusive a ansiedade de palco, têm a sua origem nesse estágio do aprendizado musical.

Outro ponto que merece destaque é a escolha do instrumento para o iniciante, em primeiro lugar no que se refere ao tamanho e material: seria melhor um violino de $1 / 2$ ou de 
3/4 de tamanho? Será que a sonoridade de uma flauta-doce de madeira de buxo não é difícil demais para a criança, em comparação com o plástico? Em segundo lugar, já o tipo de instrumento pode ser escolhido de acordo com as condições físicas: se a criança possui uma amplitude pequena da mão, talvez não o piano, mas o cravo seria a escolha mais adequada. Nesse ponto, no entanto, devem contar a simpatia do iniciante pelo instrumento e os talentos especiais. Em todos os casos, preceptoria consciente do mestre dará ao aluno a melhor condição de desenvolvimento sem lesões. E, falando em mestres, a troca de professores, em geral, traz a mudança de técnica ao instrumento por parte do aluno, seja ele jovem ou maduro, com ajustes delicados que podem desencadear dores variadas mesmo no mais calejado musicista.

\section{COMPORTAMENTO DE ESTUDO}

A atitude do músico em relação ao estudo é muito diversa. Em geral, encontram-se aqui hábitos que podem contribuir muito para o início de problemas físicos: tempo de estudo muito prolongado, poucos intervalos, falta de aquecimento, prática prolongada de dedilhados complexos e falta de atividades compensatórias à carga do estudo. Considerável é também a reação do músico em situações de dor: o conhecido lema no pain, no gain encobre o perigo da não-identificação de lesões mais graves. E a reconhecida atitude obsessivo-compulsiva do músico para atingir a perfeição, aqui, muitas vezes, não contribui para a identificação precoce e o tratamento profilático de lesões progressivamente mais graves.

\section{SEXO}

Observando os resultados das pesquisas entre músicos profissionais, percebe-se a predominância do sexo feminino no grupo dos indivíduos com problemas musculoesqueléticos. Em números, cerca de $67 \%$ a $76 \%$ das musicistas queixam-se de problemas, enquanto músicos do sexo masculino apresentam uma taxa de $52 \%$ a $63 \%^{(7,11-14)}$. Mesmo entre contrabaixistas, um grupo com relativamente poucas mulheres, essa tendência se mantém ${ }^{(4)}$. Isso leva a concluir que o sexo é predisponente para o desenvolvimento dessas queixas. Os autores presumem que a causa possa ser encontrada em três fatores: menor força muscular, menor amplitude da mão e maior ocorrência de hipermobilidade articular entre mulheres ${ }^{(7,15)}$. Hipóteses de que aspectos sociais, culturais, dificuldades de carreira e integração, assim como maior sensibilidade à dor, seriam responsáveis por essa variação são menos prováveis, uma vez que os resultados dos trabalhos, mesmo em contextos sociais diferentes, se assemelham. Além disso, o tamanho do instrumento mostra-se relativamente proporcional à prevalência de problemas em instrumentistas femininas, podendo ser evidência para a influência da força muscular e a amplitude da mão na ocorrência de queixas ${ }^{(7,15,16)}$.

\section{FATORES PSICOLÓGICOS}

Sem querer se aprofundar demasiadamente nesse campo tão extenso, devem ser aqui citados como fatores de risco a atitude quanto a pressão e expectativa - própria e do público, ansiedade de palco, labilidade emocional, assim como o clima de trabalho e a concorrência. O surgimento de distúrbios psicossomáticos é freqüente e de grande importância. Durante o exame médico, a influência dos fatores psíquicos sobre problemas físicos já existentes merece atenção especial ${ }^{(4)}$. Sobejamente conhecida é a atitude de musicistas profissionais de não procurar auxílio médico ao surgirem sinais de alerta, com receio de perda de espaço profissional e diminuição de ganho financeiro.

\section{OUTROS FATORES DE RISCO}

O papel do envelhecimento na carreira de um músico é grande - a condição física pode diminuir, enquanto as capacidades mentais e cognitivas podem lucrar com a maturidade musical e a experiência e desenvolverem-se ainda mais. Também chama a atenção o fato de muitos músicos, embora tendo grande carga física no dia-a-dia, apresentarem uma consciência corporal pouco desenvolvida. Poucos instrumentistas procuram desenvolver a propriocepção e a sensibilidade para o movimento do corpo. O que resulta em uma demora no reconhecimento de hábitos danosos à saúde - sintomas são tolerados ou nem percebidos. Também a economia dos movimentos sofre com a falta de consciência corporal. Infelizmente, já durante os estudos universitários, o resultado, ou seja, a produção musical, é visto como mais importante do que a situação física do músico. Destacam-se, ainda, como outros fatores a alimentação, a carga de trabalho, o fumo (especialmente nos instrumentistas de sopros), as condições do ambiente físico durante a prática do instrumento e a freqüente hipermobilidade constitucional $^{(17)}$. Esta última, certamente, conta como fator de risco devido à instabilidade articular decorrente, muito embora no início da carreira possa facilitar o estudo de dedilhados ou passagens mais difíceis.

O médico e o terapeuta devem ter conhecimento aprofundado desses fatores se quiserem prestar um serviço de excelência ao seu cliente musicista. No entanto, também ati- 
vidades não-musicais podem ser a origem do problema do paciente músico, como atividades esportivas, hobbies, lavar o carro, jardinagem e empregos paralelos. O diagnóstico diferencial dessas causas é obrigatório durante a avaliação clínica, eis que para o músico há a potencial situação de câmbio da sua ergonomia diante do instrumento quando é este o fator causal dos sintomas.

\section{EPIDEMIOLOGIA DE QUEIXAS MUSCULO- ESQUELÉTICAS ENTRE MÚSICOS}

\section{PREVALÊNCIA GERAL}

A quantidade e qualidade dos trabalhos até hoje publicados na área da medicina do músico mostram o quanto esse campo de pesquisa ainda está atrás de outros setores da medicina do trabalho. Há grandes diferenças no que diz respeito aos grupos examinados, parâmetros e significância. Em geral, os trabalhos se restringem a um número reduzido de probandos, sem grupo-controle. Entre as poucas pesquisas comparáveis entre si (Tabela 1 ), encontra-se uma prevalência geral de queixas musculoesqueléticas de $55 \%$ a $86 \%$ em músicos profissionais de orquestras. Essa percentagem é elevada se comparada com a de outras profissões, como, por exemplo, empregados em escritório, em que estudos indicam $37 \%$ de prevalência de queixas no sistema motor relacionadas ao trabalho ${ }^{(27)}$.

O fato de tais afecções terem sua origem já bem antes do alcance do diploma universitário é mostrado em trabalhos como o de Shoup ${ }^{(21)}$ e Lockwood $^{(14)}$, que encontraram 33\% a 49\% de prevalência de problemas entre alunos de música menores de 18 anos. Também estudantes universitários de música apresentam distúrbios no sistema motor $^{(5,23,24)}$ que podem influenciar a qualidade da interpretação e são relacionados à prática do instrumento. E, mesmo sendo o curso universitário um tempo de grandes exigências quanto à produção e ao desenvolvimento de repertório, é preciso ter consciência de que a carreira profissional que segue, em geral, não traz consigo a recuperação, mas sim a continuidade e eventual acentuação de problemas já existentes.

\section{TIPOS DE QUEIXAS}

Questionados sobre o tipo de sintomas que apresentam, os músicos mencionam como mais freqüente a queixa de dor, com $37 \%$ a $63 \%$ de prevalência ${ }^{(12,21,24,28)}$. Caso busquemos por instrumentos específicos, entre pianistas veremos a dor ocorrendo em até $98 \%$ de todos os indivíduos com problemas ${ }^{(5)}$. Outros sintomas citados são rigidez (até $49 \%$ dos músicos com sintomas), fraqueza ( $15 \%$ a $39 \%)$, fadiga ( $25 \%$ a $41 \%)$, espasmos (36\% a $46 \%$ ), edema ( $5 \%$ a $22 \%)$, tensão $(42 \%)$ e perda da resistência muscular local $(13 \%)^{(5,12,21,24,28)}$. Se considerarmos o quão incapacitante é cada uma dessas condições isoladamente, tornar-se-á mais claro o sofrimento de músicos acometidos por tais dificuldades.

\section{TIPOS DE INSTRUMENTOS}

Até pouco tempo atrás, acreditava-se que a simples escolha de um instrumento tinha papel decisivo na incidência

TABELA 1

PrevalênCia de Queixas musculoesqueléticas entre músicos

\begin{tabular}{|c|c|c|c|c|c|c|}
\hline Autores & Ano & Público-alvo & Taxa de prevalência & $\mathbf{n}$ & Prevalência & Observação \\
\hline Fry $^{(11)}$ & 1986 & Mús. de orquestra & Tempo de vida & 485 & $42 \%$ & \\
\hline Caldron e Calabrese ${ }^{(18)}$ & 1986 & Profissionais, amadores, professores e universitários & Tempo de vida & 250 & $38,6 \%$ & Sem sopros \\
\hline Lockwood $^{(14)}$ & 1988 & Menores de $18 a$ & Tempo de vida & 113 & $49 \%$ & \\
\hline Fishbein e Middlestadt(19) & 1989 & Mús. de orquestra profissionais & Tempo de vida & 2.212 & $76 \%$ & \\
\hline Mathews e Mathews ${ }^{(20)}$ & 1993 & Mús. de orquestra profissionais & Pontual & 29 & $55 \%$ & \\
\hline Larsson et al. ${ }^{(12)}$ & 1993 & Profissionais e universitários & Tempo de vida & 660 & $67 \%$ & \\
\hline Shoup ${ }^{(21)}$ & 1995 & Menores de $18 a$ & Tempo de vida & 425 & $33,2 \%$ & \\
\hline Blum ${ }^{(6)}$ & 1995 & Mús. de orquestra profissionais & Tempo de vida & 1.432 & $86,3 \%$ & Só cordas \\
\hline Salmon e Shook ${ }^{(22)}$ & 1995 & Profissionais, professores e universitários & Tempo de vida & 154 & $29 \%$ & \\
\hline Zetterberg e Blacklund(23) & 1998 & Universitários & Anual & 227 & $38,8 \%$ & \\
\hline Yeung e Chan ${ }^{(13)}$ & 1999 & Mús. de orquestra profissionais & Anual & 39 & $64,1 \%$ & \\
\hline Shields e Dockwell(5) & 2000 & Universitários & Tempo de vida & 159 & $25,8 \%$ & Só piano \\
\hline Guptill et al. ${ }^{(24)}$ & 2000 & Universitários & Tempo de vida & 108 & $87,7 \%$ & \\
\hline Rigg et al. ${ }^{(25)}$ & 2003 & Profissionais, amadores e universitários & Anual & 261 & $61,3 \%$ & Só violão \\
\hline Kaneko et al. ${ }^{(26)}$ & 2005 & Mús. de orquestra profissionais & Pontual & 241 & $68 \%$ & \\
\hline
\end{tabular}


de problemas musculoesqueléticos. Assim, por exemplo, o violino e a flauta transversa eram considerados instrumentos mais "perigosos", enquanto o cravo e os instrumentos de percussão eram tidos como mais fisiológicos. No entanto, estudos epidemiológicos encontram resultados muito divergentes quanto à prevalência geral de problemas num só instrumento: ora são os violinistas e violistas mais acometidos por problemas ${ }^{(11)}$, ora estes apresentam menos sintomas ${ }^{(14)}$. A prevalência varia de $60 \%$ a $89 \%$ entre as cordas ${ }^{(6,14)}$ e de $36 \%$ a $89 \%$ entre percussionistas ${ }^{(11,24)}$. Também não há tendências que indiquem um instrumento mais problemático entre os sopros. Em geral não é possível, portanto, declarar algum instrumento como "mais saudável", uma vez que o desenvolvimento de uma lesão depende muito mais da relação individual entre as pré-condições físicas do músico (perfil da mão, força, agilidade, postura) e as exigências do instrumento $^{(29)}$.

\section{REGIÕES DO CORPO ACOMETIDAS EM \\ RELAÇÃO AO TIPO DE INSTRUMENTO}

Entre os trabalhos mais elaborados em termos epidemiológicos, destaca-se o University of North Texas Musician's Health Survey (2000), que conseguiu isolar alguns focos sintomáticos de acordo com o instrumento praticado (Tabela 2). Assim, reconhece-se que, entre contrabaixistas com problemas musculoesqueléticos, a coluna lombar é um local freqüentemente apontado como origem de dores. Eventualmente, nesse caso, tem papel importante a postura ao contrabaixo, que exige do músico flexão e rotação constantes dos segmentos inferiores da coluna. Sem contar aquele indivíduo contrabaixista que atendemos em consultório, com severa lombalgia não devido ao ato de tocar seu instrumento, mas sim por economizar o dinheiro do táxi ao caminhar por várias quadras com seu instrumento (e a respectiva caixa protetora) às costas, diariamente, para ensaios da orquestra e dos concertos.

TABELA 2

PrevalÊNCIA DE QUeIXAS MUSCULOESQUeléticAS POR REGIão DO CORPO E INSTRUMENTO ${ }^{(\dagger}$

\begin{tabular}{|c|c|c|c|c|c|c|c|c|c|c|c|c|c|c|}
\hline & 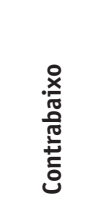 & 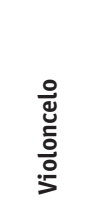 & 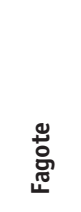 & 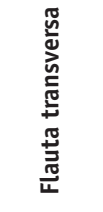 & 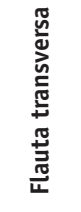 & 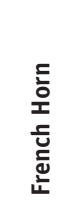 & 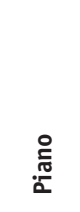 & $\frac{\circ}{\stackrel{0}{2}}$ & 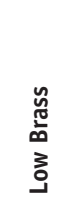 & $\begin{array}{l}\text { : } \\
\text { : }\end{array}$ & 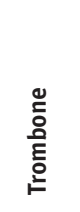 & 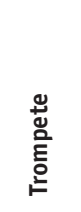 & $\stackrel{\frac{\pi}{\circ}}{\circ}$ & 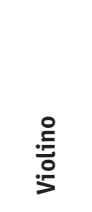 \\
\hline $\begin{array}{l}\text { Nr. Lit. } \\
\text { (n) }\end{array}$ & $\begin{array}{c}7 \\
(1.378)\end{array}$ & $\begin{array}{c}7 \\
(1.378)\end{array}$ & $\begin{array}{c}30 \\
(135)\end{array}$ & $\begin{array}{c}28 \\
(1.639)\end{array}$ & $\begin{array}{c}31 \\
(369)\end{array}$ & $\begin{array}{c}32 \\
(739)\end{array}$ & $\begin{array}{c}15 \\
(455)\end{array}$ & $\begin{array}{c}28 \\
(1.639)\end{array}$ & $\begin{array}{c}32 \\
(739)\end{array}$ & $\begin{array}{c}30 \\
(135)\end{array}$ & $\begin{array}{c}32 \\
(739)\end{array}$ & $\begin{array}{c}32 \\
(739)\end{array}$ & $\begin{array}{c}7 \\
(1.375)\end{array}$ & $\begin{array}{c}7 \\
(1.375)\end{array}$ \\
\hline Dígitos $\mathrm{D}$ & 3 & 6 & 21,3 & - & - & 12 & 25,1 & - & 19 & 25 & 7,8 & 14,8 & 5 & 4 \\
\hline Dígitos E & 12 & 16 & 30,7 & - & - & 21 & 21,1 & - & 13,3 & 10 & 15,5 & 8,3 & 11 & 10 \\
\hline Mão D & 5 & 7 & 28 & - & 31,7 & 13,2 & 24,4 & - & 17,1 & 25 & 8,8 & 13 & 5 & 6 \\
\hline Mão E & 11 & 12 & 37,3 & - & 28,5 & 16,2 & 21,8 & - & 10,8 & 8,3 & 20,7 & 9,6 & 12 & 13 \\
\hline Punho D & 7 & 8 & 33,3 & - & 38,2 & 14,4 & 34,5 & - & 22,8 & 45 & 10,4 & 13,5 & 6 & 6 \\
\hline Punho E & 7 & 7 & 48 & - & 35,2 & 16,2 & 29,7 & - & 10,8 & 18,3 & 20,2 & 12,2 & 12 & 5 \\
\hline Antebraço D & 4 & 3 & 22,7 & - & 22 & 7,2 & - & - & 8,2 & 21,7 & 6,7 & 7,8 & 6 & 5 \\
\hline Antebraço E & 5 & 6 & 26,7 & - & 19 & 9 & - & - & 4,4 & 13,3 & 11,4 & 6,1 & 7 & 6 \\
\hline Cotovelo D & 5 & 9 & 2,7 & - & 12,2 & 1,8 & - & - & 4,4 & 8,3 & 4,7 & 4,8 & 8 & 7 \\
\hline Cotovelo E & 6 & 5 & 8 & - & 11,4 & 4,2 & - & - & 5,1 & 1,7 & 10,9 & 2,6 & 5 & 4 \\
\hline Ombro D & 14 & 16 & 26,7 & - & 30,1 & 15 & - & - & 10,1 & 15 & 14 & 13,5 & 16 & 16 \\
\hline Ombro E & 8 & 11 & 26,7 & - & 28,2 & 18 & - & - & 8,9 & 11,7 & 22,8 & 8,3 & 18 & 15 \\
\hline Coluna cervical & 16 & 25 & 42,7 & 73,7 & 53,7 & 31,2 & - & 71 & 25,3 & 31,6 & 24,4 & 29,6 & 33 & 31 \\
\hline Coluna dorsal (t†) & 8 & 10 & - & 21,1 & $\begin{array}{l}14,1 \\
(\mathrm{re})\end{array}$ & 20,4 & - & 31 & 19,6 & - & 11,4 & 16,2 & 12 & 10 \\
\hline Coluna lombar (t†) & 40 & 26 & 29,3 & 27,6 & $\begin{array}{c}21,1 \\
(\mathrm{re})\end{array}$ & 41,4 & - & 35,2 & 46,9 & 33,3 & 32,2 & 36,8 & 21 & 23 \\
\hline
\end{tabular}

(†)Resultados em percentagem do total de músicos com queixas musculoesqueléticas de cada instrumento.

${ }^{(\dagger \dagger)}$ Modificado de Fishbein e Middlertadt( ${ }^{(7)}$, Rosset-Llobet et al. ${ }^{(28)}$, Thrasher e Chesky ${ }^{(30)}$, Spence et al. ${ }^{(31)}$, Chesky ${ }^{(32)}$ 
Também as queixas freqüentes de instrumentistas de sopros relacionadas ao polegar direito são influenciadas pela postura da mão, a qual carrega boa parte do peso do instrumento (Figura 3). No caso dos oboístas (o oboé é um instrumento com peso médio de $720 \mathrm{~g}$ ), o polegar direito é foco de dor em $45 \%$ dos casos, em comparação com $18 \%$ do polegar esquerdo. A flauta transversa, por sua vez, provoca o aparecimento de dor na coluna cervical de modo mais intenso do que em outros instrumentos, e a mão esquerda de violinistas apresenta em torno de duas vezes mais problemas do que a mão direita, podendo ser isto derivado da posição mais dificultosa em que se encontram punho e dedos para exercer o trabalho de dedilhado. Também interessante é o surgimento de nódulos de Heberden em violoncelistas, o que temos observado apenas na mão esquerda, a que dedilha as cordas do instrumento.

Mesmo que esses dados sirvam de base para confirmar as observações empíricas de tempos passados, não deve nunca um problema ser associado somente à postura ao instrumento. Boa parte dos músicos tolera essas condições sem apresentar distúrbios sintomáticos. Uma lesão deriva, conseqüentemente, da união de muitos fatores, sendo a postura ao tocar apenas um deles.

\section{O TERMO SUPERUSO (OVERUSE)}

A definição geral para superuso pode ser descrita como " 0 uso de um tecido além de seus limites de carga fisiológicos"(33). No entanto, no dia-a-dia, quando um músico apresenta uma disfunção musculoesquelética, é difícil a avaliação da forma e intensidade dessa lesão, sem que se tenha prova histopatológica. Fry ${ }^{(11)}$, em longos anos de prática médica em meio a músicos, desenvolveu uma classificação clínica para o superuso que se mostrou muito prática e como bom parâmetro para a avaliação de situações de dor relacionadas à prática do instrumento (Tabela 3 ).

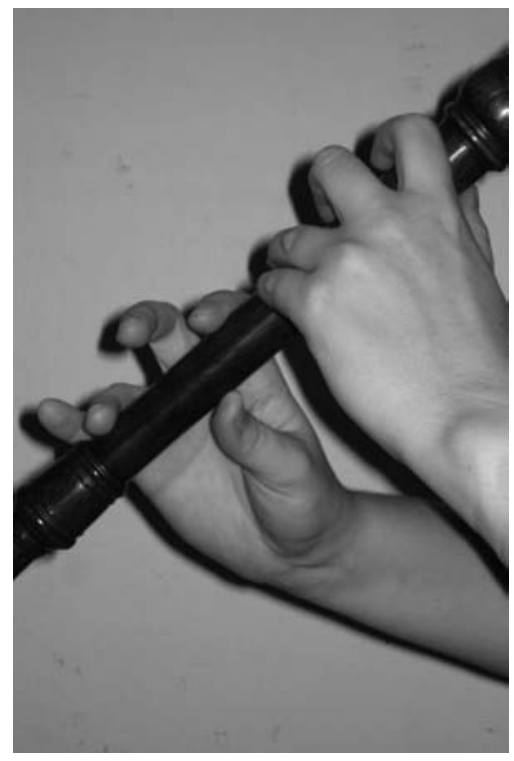

Figura 3 - Nos sopros de madeira, o polegar direito freqüentemente exerce a função de apoio único do instrumento abaixo da boca (aqui a flauta-doce como exemplo de instrumento de sopro com menor peso).

Essa classificação pode ser útil na avaliação dos problemas em músicos, uma vez que não estabelece diagnósticos, mas indica uma situação clínica muito específica.

\section{O PACIENTE MÚSICO - DIAGNÓSTICOS FREQÜENTES}

Alguns autores apresentam uma longa carreira médica em meio a pacientes do ramo musical ou artístico em geral, por exemplo, em consultórios de cirurgia de mão ou em clínicas universitárias. Os dados obtidos dessa experiência fornecem informações valiosas sobre os diagnósticos reumatológicos mais freqüentes que levam um músico a buscar auxílio médico. Especialmente os problemas da

TABELA 3

Classificação CLínica do superuso, Fry ${ }^{(11)}, 1986$

\begin{tabular}{ll}
\hline Superuso grau I & Dor unifocal durante a prática do instrumento. A dor é constante, mas termina com a finalização da atividade musical \\
Superuso grau II & $\begin{array}{l}\text { Dor multifocal durante a prática do instrumento. Sinais físicos mínimos de dor durante a pressão do tecido. Eventualmente, breve fraqueza ou } \\
\text { perda de controle. Sem distúrbios durante outras atividades da mão }\end{array}$ \\
Superuso grau III & $\begin{array}{l}\text { Dor multifocal. Dor persistente também na ausência do instrumento. Distúrbio também em outras atividades da mão, agora dolorosas. Eventual } \\
\text { fraqueza, perda de controle, perda de resposta muscular ou habilidade }\end{array}$ \\
Superuso grau IV & $\begin{array}{l}\text { Como grau III. Todas as atividades normais da mão são dolorosas - trabalhos caseiros, dirigir o carro, escrever, abrir portas, pentear os cabelos, } \\
\text { vestir-se, lavar roupa; no entanto, essas atividades são possiveis enquanto a dor é tolerada }\end{array}$ \\
\hline Superuso grau V & Como grau IV, a dor impede a utilização da mão \\
\hline
\end{tabular}


mão e dos membros superiores foram documentados de maneira mais detalhada. Se excluirmos os casos provocados por trauma, resta uma grande quantidade de diagnósticos como tendinites ${ }^{(8,9,16,34,35)}$, tenossinovite de Quervain $^{(8,9,34)}$, epicondilites ${ }^{(9,35)}$, mialgias ${ }^{(9)}$ e a já citada síndrome do superuso ${ }^{(10,16,35,36)}$. Doenças articulares degenerativas também ocorrem ${ }^{(8,37)}$, mas em número menor. $\mathrm{Ell}^{(10)}$ ressalta que uma grande parte de queixas relacionadas no passado ao superuso, ou a síndromes difusas de dor, provavelmente tem explicação em processos patológicos que, somente hoje em dia, por meio de métodos diagnósticos mais modernos, é possível reconhecer, como, por exemplo, a plica sinovial dorsal ou lesões de disco da articulação ulno-carpal.

Outros diagnósticos comuns são também dedo em gatilho $^{(34)}$, hipermobilidade ${ }^{(8)}$, instabilidade da articulação do punho $^{(10)}$, gânglions ${ }^{(8,10)}$ e a síndrome compartimental ${ }^{(36)}$.

Crianças e jovens instrumentistas, menores de 18 anos, procuram também assistência médica por causa de queixas relacionadas ao instrumento. Os diagnósticos não diferem, na maior parte, daqueles encontrados em adultos: síndrome de dor musculoesquelética, tendinopatias, tenossinovite de Quervain, epicondilite e gânglions ${ }^{(38)}$.

Não deve ser ignorado o fato de ocorrerem, muitas vezes, distúrbios neurais periféricos, e que estes devem ser considerados no momento do diagnóstico diferencial. Exemplos freqüentes são a síndrome do desfiladeiro torácico, neuropatias ulnares e a síndrome do túnel do carpo ${ }^{(39)}$.

\section{CONCLUSÕES}

Quanto mais soubermos a respeito do ambiente de vida e trabalho de nossos pacientes, mais simples, direto e eficaz será nosso contato diagnóstico e terapêutico com suas afecções. O que vale para pacientes "comuns" é transferível, da mesma forma, para o paciente músico. Uma constante na literatura da área de medicina ocupacional em músicos profissionais é a baixa qualidade científica das observações. É necessário que, no futuro próximo, sejam feitas pesquisas com enfoque mais amplo, mas também específicas sobre essa classe de pacientes. Um fator interessante, por exemplo, seria saber se as inúmeras adaptações ergonômicas, surgidas nos últimos anos, têm trazido o esperado sucesso com as queixas dos músicos. Os médicos e terapeutas que lidam com instrumentistas têm auxiliado sobremaneira esse grupo especial de pacientes, porém com métodos empíricos e sem testes pelas técnicas da medicina baseada em evidências. Vale, agora, buscar a confirmação dessa experiência em números, para conseguir o devido reconhecimento na medicina do trabalho e sem esquecer a observação de casos clínicos isolados, para que não percamos o olhar atento sobre o indivíduo e suas necessidades peculiares.

Quem deseja se aproximar da medicina do músico não necessita ser instrumentista, embora isso auxilie sobremaneira na compreensão dos aspectos peculiares aqui encontrados. Além do mais, músicos, assim como seus professores, têm um talento de observação muito acentuado no que se refere à sua técnica. $\mathrm{O}$ diálogo com eles pode indicar direções muito úteis durante o tratamento. Recomendamos a formação de uma equipe com cliente-músico no centro das atenções e, discutindo terapia e evolução clínica, o médico, o fisioterapeuta e o professor do instrumento (ou mentor mais considerado pelo musicista).

Deve-se ter precaução para não tomar conclusões precipitadas quanto ao diagnóstico, assim como evitar métodos terapêuticos generalizados e inadequados - é importante lembrar que o músico necessita do próprio corpo como ferramenta principal de trabalho. Uma terapia insuficiente ou potencialmente danosa, como aquela representada por infiltrações com má técnica ou cirurgias intempestivas, pode significar um risco à existência profissional.

O objetivo desta revisão certamente não é o de apresentar o músico na clínica médica como curiosidade, indivíduo incontestável ou artista genioso, muito pelo contrário. Músicos estão acostumados a lidar com obstáculos à sua prática, como descreve o pianista Alexis Weissenberg ${ }^{(40)}$ : "Através da experiência e do domínio absoluto do próprio aparelho motor épossivel diminuir, ou até fazer inexistentes, as dificuldades que surgem ao empregar as mãos na realização do texto musical'. Mas, infelizmente, instrumentistas por vezes não recebem a atenção específica para as suas queixas, sendo estas consideradas problemas comuns, irrisórios até. Incompreensível - pois a medicina do músico é tampouco monótona quanto misteriosa, mas sim um campo empolgante e muito variado no âmbito da medicina do trabalho e da reumatologia. Se dedicarmos a esses pacientes atenção e interesse, receberemos não só sua gratidão, mas uma visão mais sensível para avaliar também o paciente "comum", e aprenderemos a ouvir diferenciadamente as tonalidades do nosso dia-a-dia clínico. Pois também na medicina reumatológica existe um forte e um pianissimo, e ambos merecem a atenção de nossa sensibilidade profissional.

Declaramos a inexistência de conflitos de interesse. 


\section{REFERÊNCIAS}

1. Sataloff RT, Brandfonbrener AG, Lederman RJ: Textbook of performing arts medicine. New York, Raven Press, 1991.

2. Lahme A, Klein-Vogelbach S, Spirgi-Gantert I: Berufsbedingte Erkrankungen bei Musikern. Berlin, Springer, 2000.

3. Ramazzini B: (De morbus artificum diatriba) Untersuchung von denen Kranckheiten der Künstler und Handwercker. Leipzig, Weidmann, 1718.

4. Blum J: Medizinische Probleme bei Musikern. Stuttgart, Thieme, 1995.

5. Shields N, Dockwell S: The prevalence of injuries among pianists in music schools in Ireland. Med Probl Perform Art 15:155-60, 2000 .

6. Blum J: Häufigkeit, Ursachen und Risikofaktoren berufsspezifischer Erkrankungen bei Musikern. In: Wagner C: Medizinische Probleme bei Instrumentalisten: Ursachen und Prävention. Laaber, Laaber-Verlag, 1995.

7. Fishbein M, Middlestadt SE: The prevalence of severe musculoskeletal problems among male and female symphony orchestra string players. Med Probl Perform Art 4:41-8, 1989.

8. Dawson WJ: Experience with hand and upper extremity problems in 1000 instrumentalists. Med Probl Perform Art 10:128-33, 1995.

9. Sakai $\mathrm{N}$ : Hand pain attributed to overuse among professional pianists: a study of 200 cases. Med Probl Perform Art 17:178-80, 2002.

10. Ell N: Handgelenksprobleme bei Musikern. Musikphys Musikermed 4:189-202, 2003.

11. Fry HJH: Incidence of overuse syndrome in the symphony orchestra. Med Probl Perform Art 1:51-5, 1986.

12. Larsson LG, Baum J, Mudholkar GS, et al.: Nature and impact of musculoskeletal problems in a population of musicians. Med Probl Perform Art 8:73-6, 1993.

13. Yeung E, Chan W: A survey of playing-related musculoskeletal problems among professional orchestral musicians in Hong Kong. Med Probl Perform Art 14:43-7, 1990.

14. Lockwood AH: Medical problems in secondary school-aged musicians. Med Probl Perform Art 3: 129-32, 1988.

15. Pak $\mathrm{ChH}$, Chesky K: Prevalence of hand, finger and wrist musculoskeletal problems in keyboard instrumentalists: the University of North Texas Musician Health Survey. Med Probl Perf Art 16:7-23, 2001.

16. Manchester RA, Flieder D: Further observations on the epidemiology of hand injuries in music students. Med Probl Perform Art 6:11-4, 1991.

17. Seidel E, Lange E: Die Wirbelsäule des Musikers. Bad Kösen, GfBB-Verlag, 2001.

18. Caldron P, Calabrese LH: A survey of muskuloskeletal problems encountered in high level musicians. Med Probl Perform Art 1:136-9, 1986.

19. Middlestadt SE, Fishbein M: Medical problems among ICSOM Musicians. Med Probl Perform Art 3:1-14, 1988.

20. Mathews JA, Mathews W: A survey of rheumatic disorders in orchestral musicians. Med Probl Perform Art 8:14-5, 1993.
21. Shoup D: Survey of performance-related problems among high school and junior high school musicians. Med Probl Perform Art 10:100-5, 1995.

22. Salmon P, Shook CP: Performance impairments, injuries, and stress hardiness in a sample of keyboard and other instrumentalists. Med Probl Perform Art 10:140-6, 1995.

23. Zetterberg C, Backlund H: Musculoskeletal problems among male and female music students. Med Probl Perform Art 13:160-6, 1998.

24. Guptill C, Zaza C, Paul S: An occupational study of physical playing-related injuries in college music students. Med Probl Perform Art 15:86-90, 2000.

25. Rigg JL, Merriman R, Thomas MA: Playing-related injury in guitarists playing popular music. Med Probl Perform Art 18:150-2, 2003.

26. Kaneko Y, Lianza S, Dawson WJ: Pain as a incapacitating factor in Symphony Orchestra musicians in São Paulo, Brazil. Med Probl Perform Art 20:168-74, 2005.

27. Braun B, Müller R: Belastungs - und Gesundheitssituation der Berufsgruppe Bürofachkräfte. Schriftenreihe zur Gesundheitsanalyse. Band 35. St. Augustin, Asgard-Verlag Hippe, 2005.

28. Rosset-Llobet J, Rosinés-Cubells D, Saló-Orfila JM: Identification of risk factors for musicians in Catalonia (Spain). Med Probl Perform Art 15:167-74, 2000.

29. Wagner C: Hand und Instrument. Wiesbaden, Breitkopf und Härtel, 2005.

30. Thrasher M, Chesky KS: Prevalence of medical problems among double reed performers. Med Probl Perform Art 16:157-60, 2001.

31. Spence C: Prevalence Rates for medical problems among flautists: a comparison of the UNT-Musician Health Survey and the Flute Health Survey. Med Probl Perform Art 16:99-101, 2001.

32. Chesky K, Devroop K, Ford J: Medical problems of brass instrumentalists. Med Probl Perform Art 17:93-8, 2002.

33. Lederman R, Calabrese L: Overuse syndromes in instrumentalists. Med Probl Perform Art 1:7-11, 1986.

34. Dawson WJ: Upper extremity overuse in instrumentalists. Med Probl Perform Art 16:66-71, 2001.

35. Manchester RA: The incidence of hand problems in music students. Med Probl Perform Art 3:15-8, 1988.

36. Bengston KA, Schutt AH: Upper extremity muskuloskeletal problems in musicians: a follow-up survey. Med Probl Perform Art 7:44-7, 1992.

37. Hochberg FH, Leffert RD, Heller MD, et al.: Hand difficulties among musicians. JAMA 249:1869-72, 1983.

38. Burkholder KR, Brandfonbrener AG: Performance-related injuries among student musicians at a specialty clinic. Med Probl Perform Art 19:116-22, 2004.

39. Lederman R: Neuromuscular and muskuloskeletal problems in instrumental musicians. Muscle Nerve 27:549-61, 2003.

40. Bachmann R: Große Interpreten im Gespräch. München, dTV, 1978. 